\title{
Development of Ceramics Creative Process with Community-based Learning and Constructionism for Undergraduate Students
}

\author{
Saipen Cherdjerm ${ }^{1} \&$ Nirat Soodsang ${ }^{2}$ \\ ${ }^{1}$ Department of Arts and Design, Faculty of Architecture, Naresuan University, Thailand \\ Correspondence: Saipen Cherdjerm, Department of Arts and Design, Faculty of Architecture, Naresuan \\ University, Tumbon Tahpoh, Muang District, Phitsanulok Province, Thailand. Tel: 089-6407638. Fax: \\ 055-411296. E-mail: saipen@gmail.com
}

Received: March 8, 2017

doi:10.5539/ass.v13n6p65
Accepted: April 12, $2017 \quad$ Online Published: May 31, 2017

URL: https://doi.org/10.5539/ass.v13n6p65

\begin{abstract}
The purposes of this research were 1) to develop a ceramics creative process with community-based learning (CBL) and constructionism for undergraduate students; 2) to evaluate students' ceramic work with CBL and constructionism, and 3) to examine the community's and students' satisfactions towards CBL and constructionism. The research sample was selected by purposive sampling method to obtain 40 undergraduate students of Uttaradit Rajabhat University who enrolled in the Course: Local Ceramics, semester 1/2016, and 6 community instructors. Data analysis was presented by mean and standard deviation. The findings suggested that the ceramics creative process with CBL and constructionism for undergraduate students involved 5 steps, namely: 1) community survey/selection and exploring community data; 2) preparation; 3) hands-on practice to create ceramic works; 4) presentation of ceramic works; and 5) evaluation. The experimental result of the ceramics creative process with CBL and constructionism being constructed by the author revealed that the students' knowledge and understanding of ceramics creative process displayed overall mean at a very high level $(\overline{\mathrm{x}}=$ 3.70, S.D. $=0.26 ; \overline{\mathrm{x}}=3.72$, S.D. $=0.16$, respectively). The satisfaction towards CBL and constructionism were at a highest level in overall for the community and a high level in overall for students ( $\overline{\mathrm{x}}=4.67$, S.D. $=0.27 ; \overline{\mathrm{x}}=$ 3.85, S.D. $=0.34$, respectively).
\end{abstract}

Keywords: Ceramic Creative Process, Community-Based Learning, Constructionism

\section{Introduction}

Constructionism was developed by Seymour Papert, as one among the learning theories based on Piaget's theory of cognitive development. The basic tenet of Constructionism is that effective learning occurs as a result of constructing knowledge within and by learners themselves. If learners are allowed to construct an idea and bring it to create work by using appropriate technological media, such idea will become tangible. The self-constructed knowledge is meaningful, lasting and less forgetful to learner, and can be effectively conveyed for others' understanding of the learner's idea. (Tisana Khammani. 2014 pp. 4-5, 96-99).

Effective instructional management affects learner's good learning outcomes and it requires various instructional approaches or techniques, materials and media as well as learning settings or sources that facilitate effective learners' learning. At present, community is regarded as a learning source that takes crucial part in providing learners first-hand and constant learning. Learners can learn based on the authenticity of the community such as the landscape, resources, environment, history, arts, culture, traditions, wisdom, buildings, and architecture. Making use of the community in teaching and learning is one way to enable the achievement of teaching and learning. (Supanburi College of Fine Arts. 2013 p. 4) Such approach to instruction is called community-based learning (CBL) which refers to the use of community as a base of learning, an approach that focuses on learners' hands-on and real-situation learning from the community. (Boonsurb Sosome. 2010. Online) It allows for learning exchanges between students and those knowledgeable people or organizations in the community other than classroom instruction. CBL emphasizes on the so-called learning by doing or hands-on learning, and the management of knowledge including the concept, contents and process. As a result, students are encourage to interact and first-hand practice with the community as a learning resource of phenomena rather than learning from texts only. (Faculty of Humanities and Social Sciences, Kalasin Rajabhat University, 2013 p.2).

In view of the significance described above, the author thus proposed an idea of experimental study on 
instructional management for the Course: Local Ceramics, Code: 2042101, Credits: 3(2-2-5) of a Bachelor of Fine Art Program (B.F.A.) in Fine Arts, a 2012 revised curriculum, Uttaradit Rajabhat University. The study used a community as a learning source of local ceramics coupled with self-construction of knowledge by creating ceramic works in Sangkhaloke style at Baan Kohnoi, Nong-Auw sub-district, Sri Sachanalai district, Sukhothai province. It is expected that the current study result can guide further instructional management of this same approach as it is an integrated methods of teaching and learning that maximize the use of community with rich social capital.

\section{Objectives}

2.1 To develop a ceramics creative process with community-based learning and constructionism for undergraduate students;

2.2 To evaluate the ceramic works of students with community-based learning and constructionism; and

2.3 To explore the community's and students' satisfactions towards community-based learning and constructionism.

\section{Research Scope}

The current research was intended to develop a ceramics creative process with community-based learning and constructionism for undergraduate students, adopting a research and development method. It comprised 3 phrases.

Phrase 1: Synthesis of a ceramics creative process with community-based learning (CBL) and constructionism for undergraduate students. The author investigated the theories, synthesized and drafted a process model encompassing: 1) constructionism; 2) concepts, theories, and body of knowledge on ceramics; 3) community-based learning; and 4) baseline data of the intended community. All of these were taken to develop a ceramics creative process with CBL and constructionism, and also develop a handbook for developing a ceramics creative process with CBL and constructionism.

Phrase 2: Development of a ceramics creative process with community-based learning and constructionism which involved the followings.

\subsection{Specialists}

Specialists were 5 higher education instructors comprising 4 ceramics instructors and 1 instructor of curriculum and instruction or relevant fields.

\subsection{Contents}

Relevant theories were explored for ceramics creative process with CBL and constructionism, and analytical conclusions were drawn as guidelines to construct and develop research tools, and also a handbook for developing a ceramics creative process with CBL and constructionism.

\subsection{Community in the Study}

Community's context was captured and a community was selected considering its capability of CBL management, as a community that matched the Course on Local Ceramics, Code 2042101, that is, Baan Kohnoi community Nong-Auw sub-district, Sri Sachanalai district, Sukhothai province. Based on these, analytical conclusions were prepared as handbook for developing a ceramics creative process with community-based learning and constructionism.

\section{Research Instruments}

Two sets of instruments were employed: 1) an evaluation form on the development of a ceramics creative process with CBL and constructionism, and 2) a handbook for developing a ceramics creative process with CBL and constructionism.

Phrase 3: Evaluation of students' ceramic works with CBL and constructionism, and examination of community's and students' satisfactions towards CBL and constructionism. It included the followings.

\subsection{Population and Sample}

4.1.1 The population was undergraduate students of Uttaradit Rajabhat University, who enrolled in the course on local ceramics in semester $1 / 2016$.

4.1.2 The sample, selected by a purposive sampling method, was 40 undergraduate students of Uttaradit Rajabhat University, who enrolled in the course on local ceramics in semester 1/2016, and 6 community instructors. 


\subsection{Variables}

4.2.1 Independent variable was the ceramics creative process with CBL and constructionism.

4.2.2 Dependent variables:

4.2.2.1 Ceramic creative works included practical ability to create ceramic works, and knowledge and understanding in ceramic creative process.

4.2.2.2 Community's satisfaction and students' satisfaction towards CBL and constructionism.

\subsection{Duration}

In the operation to develop a ceramics creative process with CBL and constructionism for undergraduate students, the author made an operational schedule in the community for activities management by TQF Document No.3 (Course Specification) for a period of 4 days during $08.00 \mathrm{am}$. $-05.00 \mathrm{pm}$., totally 32 hours.

\subsection{Research Instruments}

The research took on the following instruments.

4.4.1 An evaluation form for the development of ceramics creative process with CBL and constructionism

4.4.2 An evaluation from for knowledge and understanding on ceramics creative process with CBL and constructionism for undergraduate students

4.4.3 An evaluation form for practical ability in ceramics creation with CBL and constructionism for undergraduate students

4.4.4 An evaluation form for community's satisfaction towards the CBL and constructionism.

4.4.5 An evaluation form on students' satisfaction towards CBL and constructionism.

\section{Research Methodology}

To carry out the ceramics creative process with CBL and constructionism for undergraduate students, the author defined the procedures below.

1. Preparing an instructional guide and TQF Document No.3 with learning specifications in 3 sessions.

Session 1: Weeks $1-6$ (24 hours), learning about the theories and principles of ceramics

Session 2: Weeks $7-8$ ( 8 hours), learning about the theories and principles of ceramics of Baan Kohnoi Sangkhaloke style, and study baseline information of Baan Kohnoi community, Nong-Auw sub-district, Sri Sachanali district, Sukhothai province. (Week 9: Midterm exam).

Session 3: Weeks $10-17$, undertaking a field study and doing activities of ceramic creative process with CBL and constructionism by creating ceramic works in Sangkhaloke style at Baan Kohnoi Nong-Auw sub-district, Sri Sachanali district, Sukhothai province. To manage activities, the author set a hands-on practice in the community at weeks $10-13$, with 4 days of learning activities from 08.00 am to 05.00 pm., making altogether 32 hours (for convenience of students' commuting and practice and at the same time allowing for the community's preparation of materials/ instruments/equipment and spaces of activities) (Figures 1-4).

2. Preparing a handbook for developing a ceramics creative process with CBL and constructionism: a case study of making Sangkhaloke at Baan Kohnoi Nong-Auw sub-district, Sri Sachanali district, Sukhothai province.

3. Organizing the teaching and learning as identified in the instructional guide and TQF Document No.3, and in the handbook for developing a ceramics creative process with CBL and constructionism: a case study of making Sankhaloke at Baan Kohnoi Nong-Oor sub-district, Sri Sachanali district, Sukhothai province.

4. Requesting for approval by the Faculty/University of locating students for the study and practical learning at Baan Kohnoi Nong-Auw sub-district, Sri Sachanali district, Sukhothai province.

5. Constructing evaluation forms for community's and students' satisfactions towards CBL and constructionism.

6. Reviewing both satisfaction evaluation forms by specialists as 5 higher education instructors, i.e. 4 ceramics instructors and 1 instructor of curriculum and instruction or other related fields.

7. Evaluating at post-learning the community's and students' satisfactions towards CBL and constructionism with their ceramic creative works.

8. Performing analyses, drawing conclusions, and providing discussion of results.

The learning activities of ceramics creative process with CBL and constructionism were illustrated in Figures 
$1-4$.

1. Learning activity in bodies preparation step

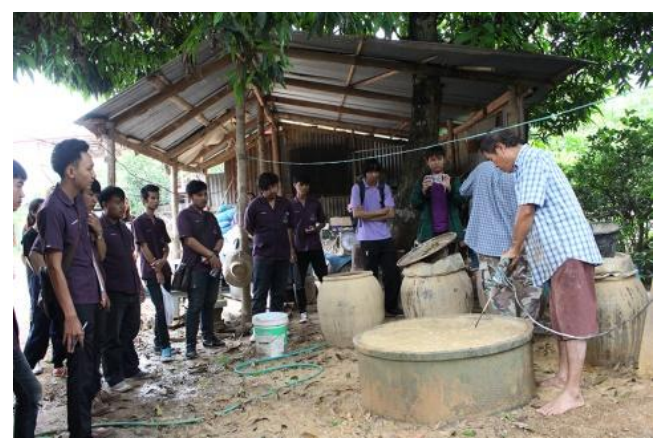

(1)

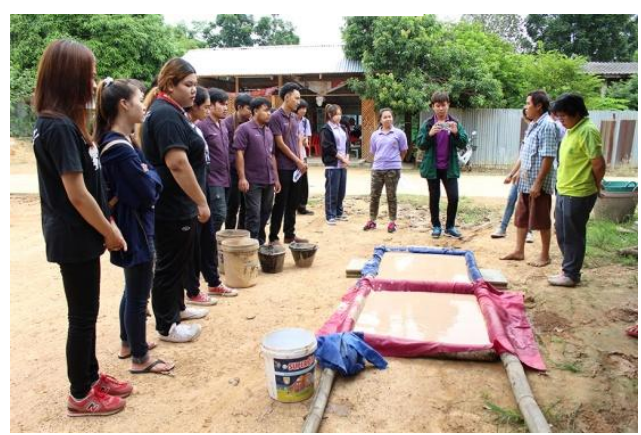

(3)

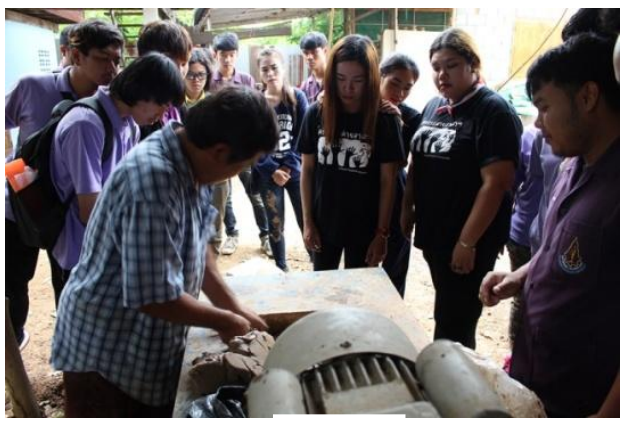

(5)

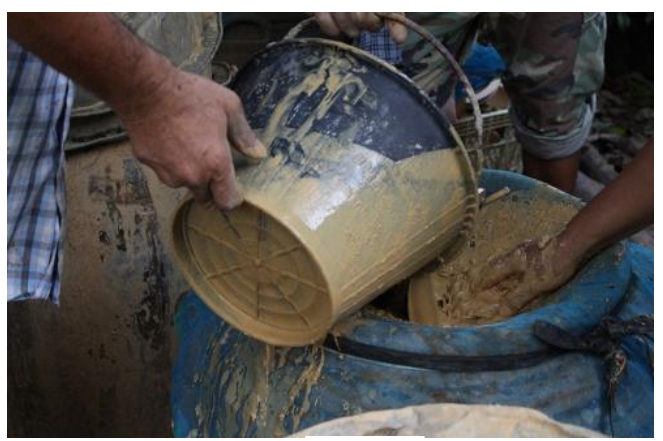

(2)

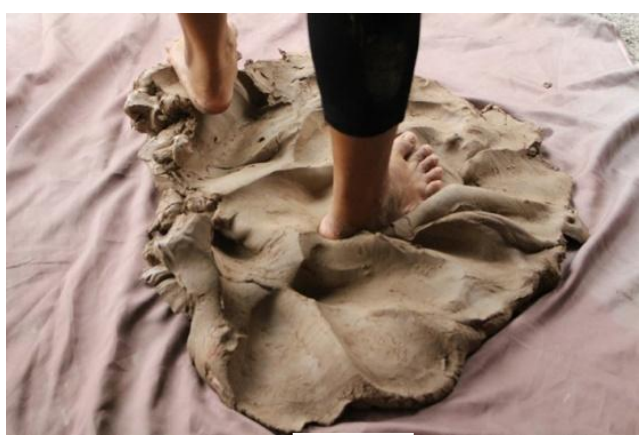

(4)

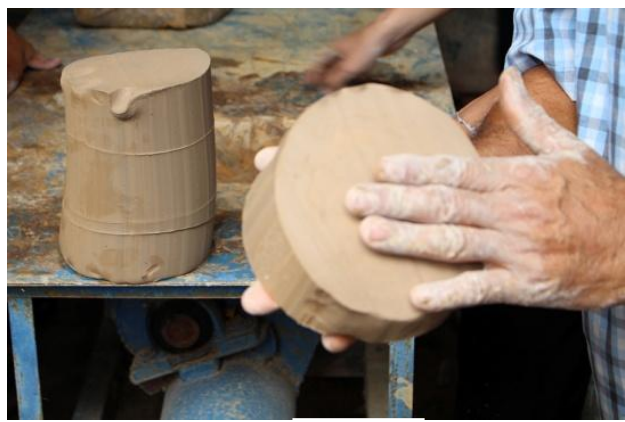

(6)

Figure 1. Learning activity in clay bodies preparation processing (1) Use the drill to blend the clay previously leaven for at least 2 days, (2) Filter liquid clays, (3) Bring filtered liquid clays to sunlight, (4) Once half-dry, tread the clay by foot, (5) Knead the clay with roller to remove air bubbles, (6) The appearance of roller-kneaded clay 
2. Examples of learning activities and practice: How to build Naga
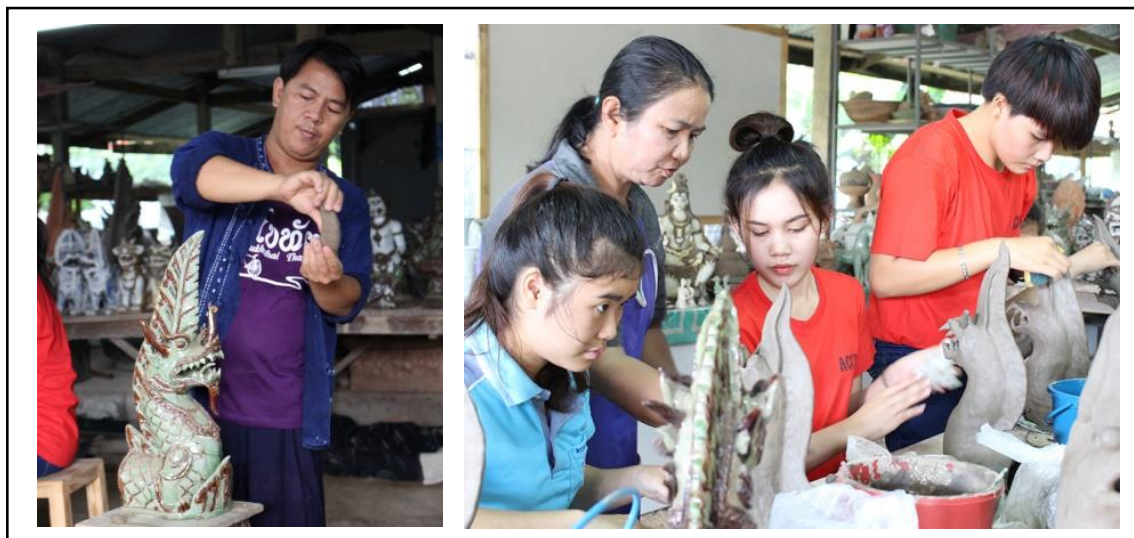

(1)
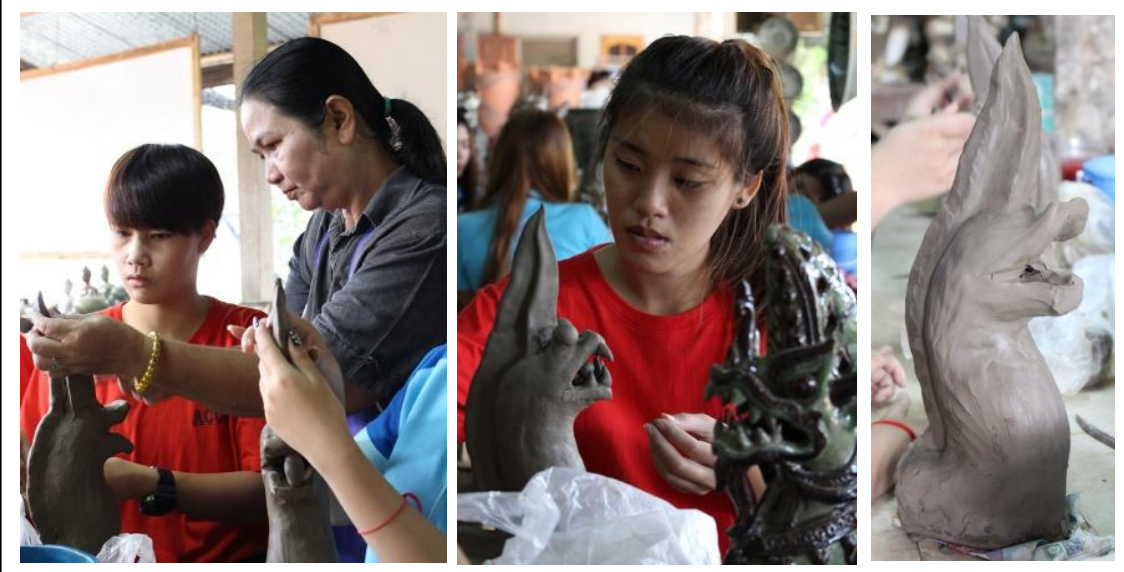

(2)
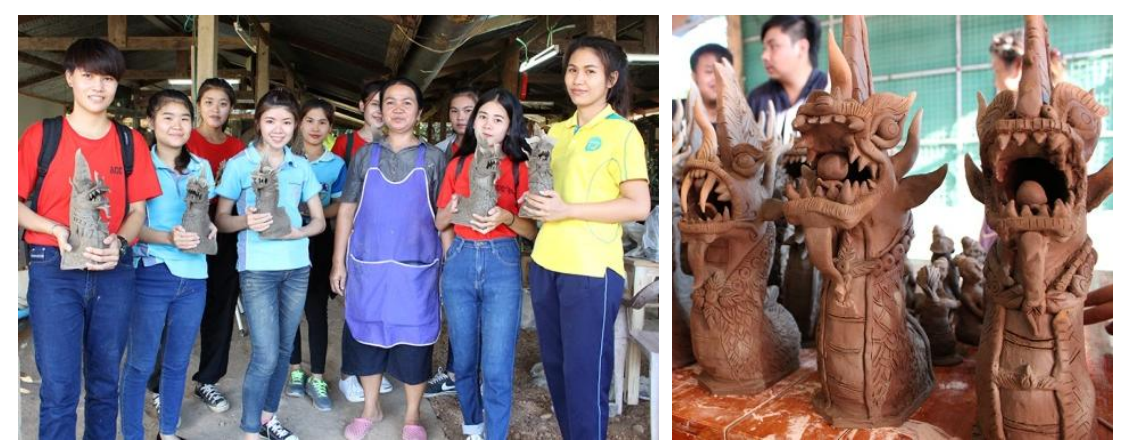

(3)

Figure 2. Examples of learning and practical activities of how to build ceramics: (1) Building Naga, (2) Community instructors' demonstration of how to build Naga/student's practice building Naga, (3) Finished Naga. 
3. Learning and practical activities on decoration with glazes.

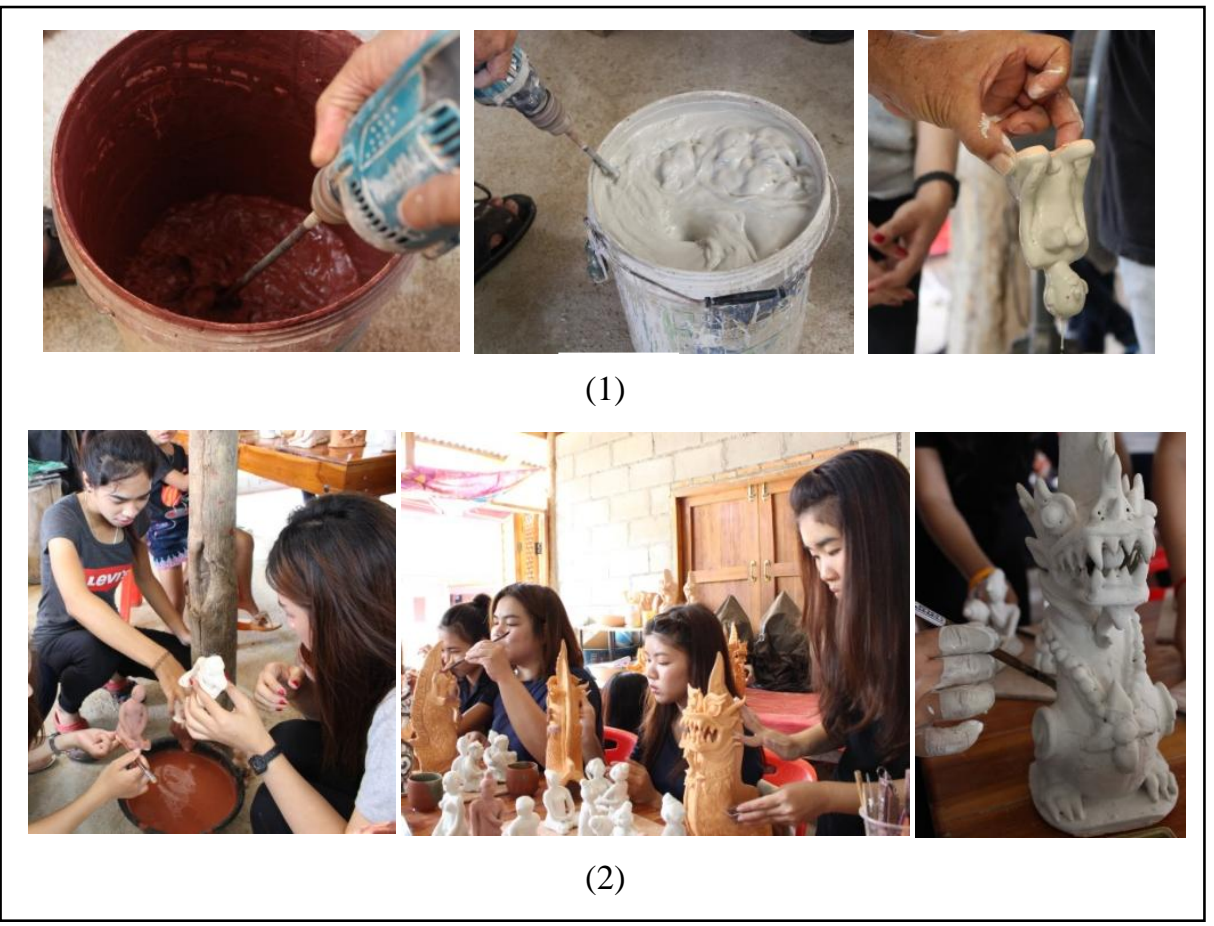

Figure 3. Learning activities on decoration with glazes (1) Community instructors' demonstration of how to prepare liquid glaze, (2) Student's practice of glaze dipping/graze brushing.

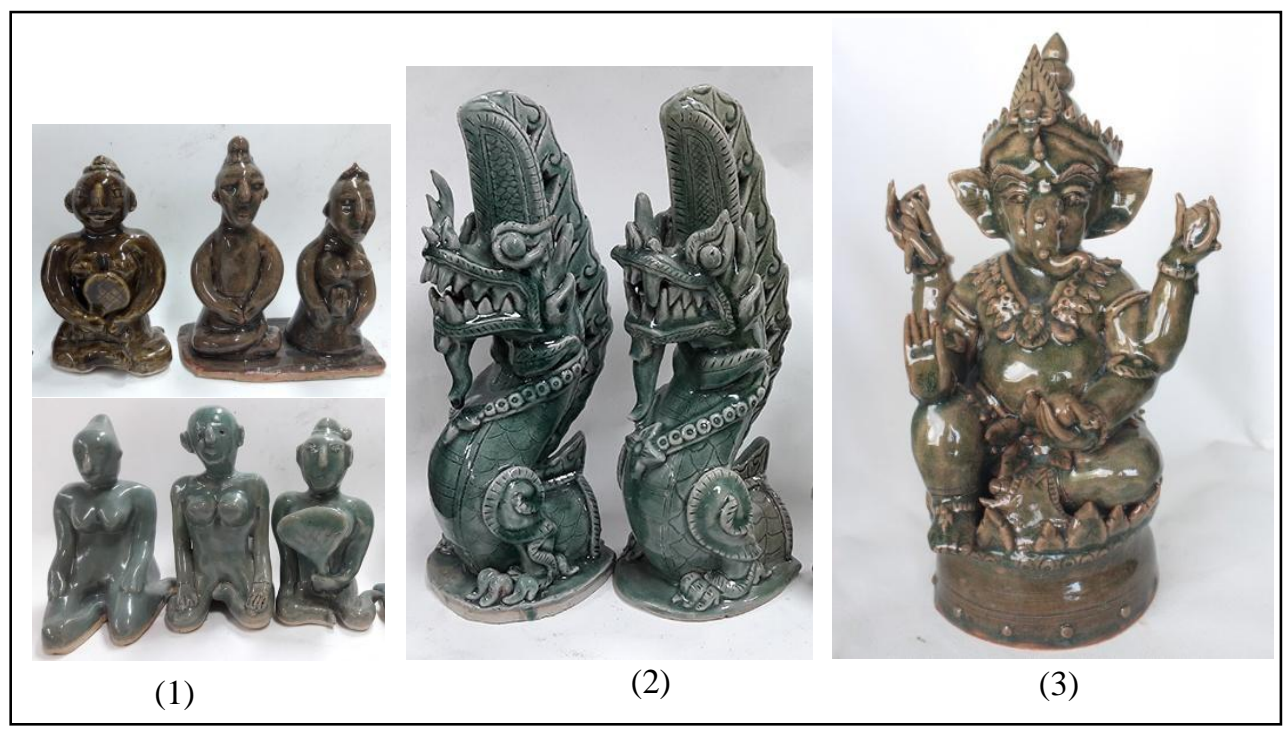

Figure 4. Samples of student's finished works by ceramics creative process with CBL and constructionism: (1) Human dolls, (2) Naga, and (3) Ganesha

\section{Conclusions and Discussion}

Based on the current work to develop a ceramics creative process with CBL and constructionism for undergraduate students, the results were summarized and discussed by 3 phrases described below.

Phrase 1 and phrase 2 aimed at developing a ceramics creative process with CBL and constructionism for 
undergraduate students. At phrase 1, the author examined and synthesized the data pertaining to 1) constructionism, 2) community-based learning, and 3) ceramics creative process. Phrase 2 drew on the data from phrase 1 to the analysis and development of a ceramics creative process with CBL and constructionism, as depicted in the following chart.

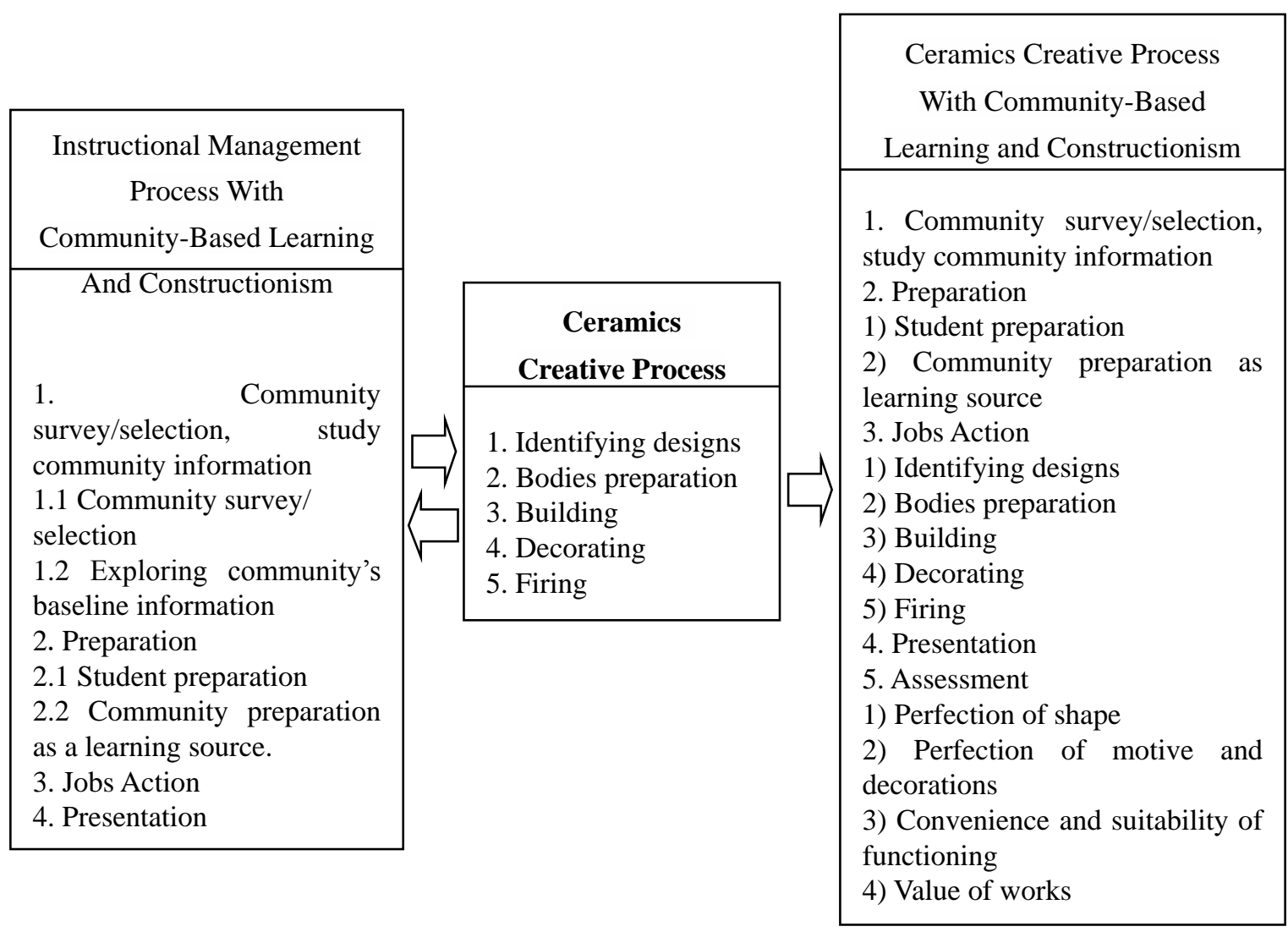

Figure 5. Ceramics creative process with community-based learning and constructionism

By following the above process, the author developed a handbook for developing a ceramics creative process with CBL and constructionism based on the opinions and suggestions of advisors and specialists on the components and contents of the ceramics creative process and the handbook. The test results of evaluation forms provided IOC in a range of $0.80-1.00$, suggesting a high level of propriety of the evaluation forms being constructed by the author. Next, the author employed both the ceramics creative process and the handbook to further manage the instruction and carry out the research and data collection in phrase 3 .

Phrase 3 was intended to 1) evaluate the ceramic works of students with CBL and constructivism, and 2) evaluate the community's and students' satisfaction towards CBL and constructivism. These evaluations were undertaken at post-experiment of the process using the author's constructed evaluation forms which were reviewed by advisors and specialists on the components and contents pertaining to the process. At this phrase, 2 parts of evaluations were conducted using these forms. 1) Evaluation forms for students' ceramic works comprising 1.1) an evaluation form for knowledge and understanding in ceramics creative process with KBL and constructivism, and 1.2) an evaluation form for practical ability of creating ceramic works with CBL and constructivism. The results of specialists' evaluation provided IOC in a range of $0.80-1.00$ for both sets of evaluation forms. This suggested that the author's constructed evaluation forms offered high level of propriety. 2) Satisfaction evaluation forms contained 2 sets, i.e. 2.1) an evaluation form for community's satisfaction towards CBL and constructivism, and 2.2) an evaluation form for student's satisfaction towards CBL and constructivism. As evaluated by specialists, the IOC ranged between $0.80-1.00$, representing a high level of propriety of the author's constructed evaluation forms.

The results of phrase 3 were summarized as follow.

1. Evaluation result of students' ceramic works with CBL and constructivism, by knowledge and understanding, 
and practical ability.

1.1 Evaluation result of knowledge and understanding in ceramics creative process with CBL and constructivism. Students reported their knowledge and understanding of the process with overall mean at a high level $(\overline{\mathrm{x}}=3.72$, S.D. $=0.13)$. Considering by different types of ceramic works, the human doll, Naga, and Ganesha also provided means representing a high level $(\overline{\mathrm{x}}=3.73$, S.D. $=0.20 ; \overline{\mathrm{x}}=3.77$, S.D. $=0.17$; and $\overline{\mathrm{x}}=3.66$, S.D. $=0.17$, respectively).

1.2 Evaluation result of practical ability to create ceramic works with CBL and constructivism. Students' practical ability displayed overall mean at a high level $(\overline{\mathrm{x}}=3.70$, S.D. $=0.13)$. Likewise, different types of creative works, i.e. human doll, Naga, and Ganesha presented means at a high level $(\overline{\mathrm{x}}=3.71$, S.D. $=0.19 ; \overline{\mathrm{x}}=$ 3.77, S.D. $=0.17$; and $\overline{\mathrm{x}}=3.62$, S.D. $=0.16$, respectively.)

2. Evaluation result of community's and students' satisfactions towards CBL and constructivism.

2.1 Evaluation result of community's satisfaction towards CBL and constructivism suggested a highest level of mean $(\bar{x}=3.46$, S.D. $=0.27)$.

2.2 Evaluation result of students' satisfaction towards $\mathrm{CBL}$ and constructivism suggested a high level of mean ( $\overline{\mathrm{x}}$ $=3.85$, S.D. $=0.34$ ).

From phrase 1 and 2, what obtained was a ceramics creative process with CBL and constructivism for undergraduate students which contained 5 steps consisting of 1) Community survey/selection, study community information; 2) Preparation: student preparation and community preparation as learning source; 3) Jobs action : identifying designs, bodies preparation, building, decorating, and firing; 4) presentation of ceramic works; and 5) Presentation: perfection of shape, perfection of motive and decorations, convenience and suitability of functioning, and value of works. This process agreed to Nutthakritta Sirisopon (2013) who developed a web-based instruction model under constructivism for critical thinking development which included 10 phrases, i.e.1) Critical preparation, 2) Review the issue, 3) Elaborate learning, 4) Arranging data, 5) Thinking and diagnosing, 6) Interpersonal communication, 7) Verify the solution, 8) Implementation, 9) Transfer of innovations, and 10) Yielding evaluation. Additionally, Supattra Sirijamorn's (2014) "SUPAT Model" had 5 steps, i.e. 1) S: Start preparing; 2) U: Understand concept; 3) P: Process by Practice; 4) A: Application; and 5) T: Total for constructing.

Phrase 3 involved evaluations of 1) Students' ceramic works with CBL and constructivism, and 2) Community's and students' satisfactions towards CBL and constructivism. With respect to students' ceramic work being evaluated in 2 aspects of students' knowledge and understanding on the process and students' practical ability to create ceramic works, the evaluation results demonstrated the overall mean for the 2 aspects at a very high level $(\overline{\mathrm{x}}=3.73$, S.D. $=0.26$; and $\overline{\mathrm{x}}=3.72$, S.D. $=0.16$, respectively $)$. The results were in accord with Sopone Phonprapruit (2014) who developed an instructional model with online project-based learning by constructionism, and reported that $83.33 \%$ of students demonstrated a very high level of learning achievement, and a high level in every aspects of capacity development with online project-based learning. Similarly, Pattanee Muangjaima (2011) found that the instructional management process based on constructionism allowed students to develop their knowledge and enhance experience from the learning source in reality. It also reported students' learning achievement passing the educational criterion standards and a very high level (97.00\%) of desirable characteristics acceptable by parents and community. Regarding the current evaluation results of community's and students' satisfactions towards the process, they suggested the community's satisfaction with overall mean at a highest level $(\overline{\mathrm{x}}=4.67$, S.D. $=0.27)$, whereas it was at a high level $(\overline{\mathrm{x}}=3.85$, S.D. $=0.34)$ for students. Thawatchai Sahapong (2013) in his study on the learning outcome with constructionism for the course on animation for multi-media, found students' satisfaction at a high level in overall with mean of 4.30, and standard deviation of 0.41 . For the current result of community's satisfaction evaluation, the author focused on the samples as community instructors who transferred their knowledge to students, and their satisfaction was found with mean at a highest level in overall $(\overline{\mathrm{x}}=4.67$, S.D. $=0.27)$ which was the highest for the current research results. With the author's informal observation and inquiry, the community was found happy to convey their wisdom and was active as a learning source for it is their wish that students and instructors as well as interested public know, value, and preserve the local or community career and wisdom. This result was supported by Nirat Soodsang (2016) who pointed out that learning in the community promotes participatory learning process, maintain and build the capacity of local wisdom, and build the network and collaboration to link the knowledge and local wisdom. As argued by Chaidet Kaewsanga (2013) on the learning by Constructionism and community-based learning that these approach encourage students to construct new body of knowledge by connecting it with previous knowledge and enable their application of knowledge in reality. Students develop 
skills through hands-on with their own idea to construct their works. Community or local sages also involves in learning management. It is a sustainable, systematic learning exchange process between educational institution and community.

\section{Recommendations}

The present research results can be further adapted and extended by those interested individuals for the development of instructional management process in other courses so as to allow for and create students' new experiences outside of the classroom. In particular, learning in the community with rich social capital and distinguish culture will add confidence to and highlight community people's sense of love, pride, and conservative in their local career. Moreover, it is another way to foster, carry on and preserve local wisdom so they will not disappear from the community, society, and country.

\section{Acknowledgement}

This research was funded by the Department of Arts and Design, Faculty of Architecture, Naresuan University, and Uttaradit Rajabhat University. The author would like to thank those learning sources in the community including Prasert Antique and Ket-Anong Shop at Baan Kohnoi, Nong-Auw sub-district, Sri Sachanalai district, Sukhothai province for their assistance and facilitation in exploring the data, and also thank the Fine Arts Program and the Faculty of Humanities and Social Sciences, including those administrators for their support and facilitation in doing this research. The author extends sincere appreciation to advisors and experts for their review of research instruments and contribution to make this research successfully completed.

\section{References}

Sirisopon, N. (2013). The Development of a Web-Based Instruction Model Under Constructionism for Critical Thinking Development. Dissertation for Ed.D. (Educational Technology), Kasetsart University. Bangkok.

Department of Humanities and Social Sciences, Kalasin Rajabhat University. (2014). Research Report on Community-Based Learning Management. Kalasin Rajabhat University. Kalasin.

Kaewsanga, C. (2013). The Development of Learning Activity Focus on the Learner by Using Constructionism in 235575 Pottery Course of Second Year Students in Department of Art Education, Faculty of Education, Khon Kaen University. Journal of the Institute of Culture and Arts. (Online). Retrieved May 21, 2014, from http://www.tci-thaijo.org/index.php/jica/article/view/15157

Khammani, T. (2014). Science of Teaching: Body of Knowledge for Effective Management of Learning Process (18th ed.). Bangkok: Chulalongkorn University Press.

Sahapong, T. (2012). The Learning Outcome with Constructionism for the Course on Animation for Multi-media. A research report. Rajabhat Mahasarakham University. Mahasarakham.

Sosome, B. (2010). Community-based Learning. (Online). Retrieved May 21, 2014, from http://webcache.googleusercontent.com/search?q=cache:OI7KMlKSrUkJ:61.7.221.149/KMwebsite/Km/ch umchon\%2520(2).ppt $+\& \mathrm{~cd}=1 \& \mathrm{hl}=\mathrm{th} \& \mathrm{ct}=\mathrm{clnk} \& \mathrm{gl}=\mathrm{th}$

Muangjaima, P. (2011). An Evaluation of Educational Management System by Constructionism of Municipality School 4, Muang District, Lampang Province (M.P.A.Thesis). Khonkaen Unuversity, Khonkaen province.

Supanburi College of Fine Arts. (2013). Community-Based Instructional Technique. A report paper, Bunditpatanasilpa Institute. Supanburi.

Sirijamorn, S. (2014). Format of the Learning Activities Using Community-based Development of Science Process Skills and Environmental Awareness: A Case Study of Saline in Nonthaikaruupatam 2 School. (Online). Retrieved August 15, 2015, from http://www.nma6. go.th/office/28524

Phonprapruit, S. (2014). Development of Instructional Model with Online Project-Based Learning Based on Constructionism. Dissertation for Ed.D. (Educational Technology). Kasetsart University. Bangkok.

Soodsang, N. (2017). Effects of Community-Based Learning in Ceramics, Sukhothai Sangkaloke. Asian Social Science, 13(2), 41-48. https://doi.org/10.5539/ass.v13n2p41

\section{Copyrights}

Copyright for this article is retained by the author(s), with first publication rights granted to the journal.

This is an open-access article distributed under the terms and conditions of the Creative Commons Attribution license (http://creativecommons.org/licenses/by/4.0/). 